\title{
A Heuristic Approach For Firewall Policy Optimization
}

\author{
El-Alfy, ESM \\ IEEE, 9TH INTERNATIONAL CONFERENCE ON ADVANCED COMMUNICATION \\ TECHNOLOGY: \\ TOWARD NETWORK INNOVATION BEYOND EVOLUTION, VOLS 1-3; pp: 1782-1787;
}

Vol: \#\#

King Fahd University of Petroleum \& Minerals

http://www.kfupm.edu.sa

\begin{abstract}
Summary
A primary goal of this paper is to develop a heuristic approach based on genetic algorithms to enhance the firewall performance. Typical firewall policies may have thousands of rules and determining an optimal rule order that minimizes the average number of rule comparisons while maintaining the policy integrity is proven to be NP-hard. This problem is formulated as a binary integer program for which an optimal solution is obtained using the branch-and-bound technique. Then. an alternative solution approach is devised based on genetic algorithms. Several experiments are conducted to evaluate the effectiveness of the proposed approach as compared to other rule-ordering techniques. Empirical results show the potential and flexibility of the proposed approach.
\end{abstract}

\section{References:}

1. ADAMIC L, 2002, GLOTTOMETRICS, P143

2. ALSHAER E, 2003, P IEEE IFIP INT MAN, P17

3. ALSHAER E, 2005, IEEE J SEL AREA COMM, V23, P2069

4. BARTAL Y, 2004, ACM T COMPUT SYST, V22, P381

5. BELLOVIN SM, 1994, IEEE COMMUN MAG, V32, P50

6. FULP E, 2005, P 9 IFIP IEEE INT S

7. FULP EW, 2005, P 10 IEEE S COMP COM, P434

8. GEN M, 2000, GENETIC ALGORITHMS E

9. GOUDA MG, 2004, P 24 IEEE INT C DIST, P320

10. HAMED H, 2006, P INFOCOM APR

11. HAZELHURST S, 2000, P INT C DEP SYST NET, P576

12. MAYER A, 2000, P IEEE S SECUR PRIV, P177

copyright: King Fahd University of Petroleum \& Minerals; http://www.kfupm.edu.sa 
13. NEMHAUSER G, 1988, INTEGER COMBINATORIA

14. PREISS B, 1999, DATA STRUCTURES ALGO

15. QIU L, 2001, P 9 INT C NETW PROT, P241

16. YAMADA T, 1997, P MOD HEUR DEC SUPP

17. YUAN L, 2006, P IEEE S SEC PRIV MA

18. ZALENSKI R, 2002, IEEE POTENTIALS, V21, P24

For pre-prints please write to: abstracts@kfupm.edu.sa 